\title{
Techniques
}

\section{Comparison of Breast Carcinoma Prognostic/ Predictive Biomarkers on Cell Blocks Obtained by Various Methods: Cellient, Formalin and Thrombin}

\author{
Blythe K. Gorman ${ }^{a}$ Ognjen Kosarac ${ }^{a}$ Subhendu Chakraborty ${ }^{a}$ \\ Mary R. Schwartz ${ }^{a}$ Dina R. Mody ${ }^{a}$ b \\ a Department of Pathology and Genomic Medicine, The Methodist Hospital, Houston, Tex., and \\ ${ }^{b}$ Department of Pathology and Laboratory Medicine, Weill Medical College of Cornell University, \\ New York, N.Y., USA
}

\section{Key Words}

Biomarkers $\cdot$ Breast carcinoma $\cdot$ Cell block $\cdot$ Cellient $\cdot$

Cytology $\cdot$ Fine needle aspiration $\cdot$ Immunohistochemistry

\begin{abstract}
Objective: To compare results of immunohistochemical (IHC) assays for estrogen receptor (ER), progesterone receptor (PR) and human epidermal growth factor receptor 2 (HER2) performed on thrombin, formalin and Cellient cell blocks to those performed on tissue. Study Design: Formalin, thrombin and Cellient cell blocks were prepared from cytologic samples obtained from resection specimens of 31 patients with invasive breast carcinoma. ER, PR, HER2 and MIB-1 (Ki-67) IHC stains were performed on all three types of cell blocks and compared to the same stains performed on the patient's paraffin-embedded biopsy or resection. Cell and tissue blocks with equivocal staining for HER2 were submitted for fluorescence in situ hybridization (FISH). Results: Adequate Cellient blocks were obtained for all 31 cases. Comparison of results of ER IHC assays on all three types of cell blocks showed $100 \%$ correlation with tissue. Both Cellient and thrombin blocks showed $100 \%$ correlation with tissue for HER2 IHC and FISH results. The only statistically significant difference between cell block methods was found in
\end{abstract}

PR staining, where false-negative results occurred with Cellient and thrombin blocks. Conclusion: Breast biomarker IHC assays performed on Cellient blocks are reliable and correlate with tissue block results, particularly for ER and HER2, the most clinically important markers.

Copyright $\odot 2012$ S. Karger AG, Basel

\section{Introduction}

Immunohistochemical (IHC) stains for breast carcinoma biomarkers are currently performed on a patient's biopsy or surgical resection. The use of cytologic samples for determining a patient's estrogen receptor (ER), progesterone receptor (PR) and human epidermal growth factor receptor 2 (HER2) status has yet to be validated, in part due to the decline in breast fine needle aspiration (FNA) procedures. The feasibility of adhering to the American Society of Clinical Oncology/College of American Pathologists (ASCO/CAP) guidelines regarding formalin fixation and the quality of IHC results using cyto-

This study was presented in part at the Texas Society of Pathologists Annual Meeting, San Antonio, Tex., USA, January 14, 2011.

\section{KARGER}

Fax +41613061234

E-Mail karger@karger.ch

www.karger.com
(C) 2012 S. Karger AG, Basel

0001-5547/12/0563-0289\$38.00/0

Accessible online at:

www.karger.com/acy
Correspondence to: Dr. Blythe K. Gorman

Department of Pathology and Genomic Medicine, The Methodist Hospital 6565 Fannin Street, Suite M227

Houston, TX 77030 (USA)

Tel. +1 713441 6420, E-Mail bkgorman@tmhs.org 
Table 1. Results of IHC stains for ER, PR, and HER2 and HER2 FISH performed on tissue blocks

\begin{tabular}{|c|c|c|c|c|}
\hline $\begin{array}{l}\text { Number of cases } \\
(\mathrm{n}=31)\end{array}$ & ER & PR & $\begin{array}{l}\text { HER2 } \\
\text { IHC }\end{array}$ & $\begin{array}{l}\text { HER2 } \\
\text { FISH }\end{array}$ \\
\hline 15 & positive & positive & negative & $\mathrm{N} / \mathrm{A}$ \\
\hline 3 & positive & positive & equivocal & negative \\
\hline 3 & positive & negative & negative & N/A \\
\hline 7 & negative & negative & negative & N/A \\
\hline 2 & negative & negative & positive & N/A \\
\hline 1 & negative & negative & equivocal & negative \\
\hline
\end{tabular}

HER2 IHC negative $=$ Score 0 or $1+$; HER2 IHC equivocal $=$ score 2+; HER2 IHC positive = score $3+; \mathrm{N} / \mathrm{A}=$ not applicable.

Table 2. IHC assays performed on cell blocks and tissue blocks

\begin{tabular}{lllll}
\hline Antibody & Clone & Manufacturer & Location & Dilution \\
\hline ER & SP1 & Ventana & Oro Valley, AZ & prediluted \\
PR & 1E2 & Ventana & Oro Valley, AZ & prediluted \\
HER2 & PN2A & DakoCytomation & Denmark & $\begin{array}{l}\text { prediluted } \\
\text { prediluted }\end{array}$ \\
Ki-67 & MIB-1 & DakoCytomation & Denmark & Denork \\
\hline
\end{tabular}

logic samples is currently uncertain. The ASCO/CAP guidelines recommend that biomarker assays should be performed on every new recurrence $[1,2]$. Many of these lesions are initially sampled by FNA only, so the use of cytologic samples for determining hormone receptor status by IHC is of increasing clinical importance. As with any new procedure, validation prior to clinical implementation is necessary.

\section{Materials and Methods}

\section{Case Selection and Sample Collection and Processing}

This study was approved by The Methodist Hospital Research Institute Institutional Review Board (Pro00005709). Surgical resections (mastectomy or lumpectomy) from 31 patients with biopsy-proven invasive mammary carcinoma and a grossly visible lesion were sampled. If no lesion was identified grossly, or if the integrity of the specimen would be compromised by sampling procedure, no specimen was collected. No other criteria for exclusion were used. Patients were not excluded based on history of treatment. The patients included 30 women and 1 man. They ranged in age from 36 to 81 years (average age, 59 years). Histologic types included ductal $(77.4 \% ; 24 / 31)$, lobular $(12.9 \% ; 4 / 31)$ and mucinous $(9.7 \% ; 3 / 31)$. Many of the patients $(41 \% ; 13 / 31)$ had poorly differentiated carcinomas, i.e. Elston-Ellis modification of Scarff-Bloom-Richardson grading system (ESBR) scores of $8-9$. Ten patients $(32.3 \%)$ had moderately differentiated (ESBR $6-7)$ carcinomas and $8(25.8 \%)$ had well-differentiated (ESBR 3-5) carcinomas. The majority of tumors were ER-positive, PRpositive and HER2-negative (table 1). Scrapings were obtained from each tumor and collected in three types of media including a methanol-based fixative, CytoLyt (Hologic Corp., Marlborough, Mass., USA), formalin and Roswell Park Memorial Institute medium (Mediatech Inc., Manassas, Va., USA). The material collected in CytoLyt was used to prepare a Cellient cell block according to the instructions given by the manufacturer. The Cellient cell blocks are made using the automated Cellient system, which does not use formalin in the production of the cell block and requires approximately $1 \mathrm{~h}$ to prepare. As additional processing is not required, the Cellient blocks could be submitted promptly for histologic sectioning. The material collected in formalin was allowed to fix for $1 \mathrm{~h}$ and centrifuged. The cell pellet was wrapped in lens paper and submitted for histologic processing after appropriate formalin fixation. The material collected in the Roswell Park Memorial Institute medium was centrifuged, and then mixed with plasma and thrombin to form a clot, which was wrapped in lens paper and submitted for histologic processing after appropriate formalin fixation. The formalin and thrombin cell blocks were processed according to the protocol for breast core biopsies using a Leica Peloris processor. Three and a half hours of the 8-hour processing cycle involved additional formalin fixation. Ten sections were cut from each of the cell blocks. Hematoxylin and eosin stain was performed on levels 1, 5 and 10 to assess the adequacy of the sample and IHC stains were performed on the unstained levels with the highest cellularity. If the material was still insufficient after 10 sections, an additional 10 sections were cut with hematoxylin and eosin stain performed on levels 11,15 and 20 .

\section{Fixation and Immunohistochemistry for ER, PR, HER2 and $M I B-1$}

The formalin and thrombin cell blocks were fixed in 10\% neutral buffered formalin according to the ASCO/CAP guidelines, while the Cellient cell blocks were not processed in formalin. Although the Cellient cell blocks were not exposed to formalin, slides made from Cellient cell blocks were incubated in $10 \%$ neutral buffered formalin for $10 \mathrm{~min}$ prior to IHC staining. The formalin incubation step is not listed by the manufacturer as a requirement, but it was adopted by our lab during optimization. The tissue blocks from surgical or biopsy specimens were placed in formalin and fixed for between 6 and $48 \mathrm{~h}$. All unstained slides prepared for IHC staining were submitted for staining within 1-2 weeks of preparation. In cases which required repetition of stains, the unstained sections were submitted for staining within 6 weeks of preparation. Otherwise, new sections were cut from the cell block. IHC staining for ER, PR, HER2 and MIB-1 was performed on all three types of cell blocks according to instructions given by the manufacturers (table 2). IHC stains for ER, PR and MIB-1 were performed using the Ventana Benchmark XT (Ventana, Oro Valley, Ariz., USA) series automated stainer. IHC staining for HER2 was performed using the Dakoautostainer (DakoCytomation, Denmark). FISH was performed on both tissue and cell block sections with equivocal IHC for HER2. 
Fig. 1. Examples of the three types of cell blocks in comparison to paraffin-embedded tissue. a Cellient cell block. b Formalin cell block. c Thrombin cell block. d Paraffin-embedded tissue block. HE. Original magnification $\times 400$.
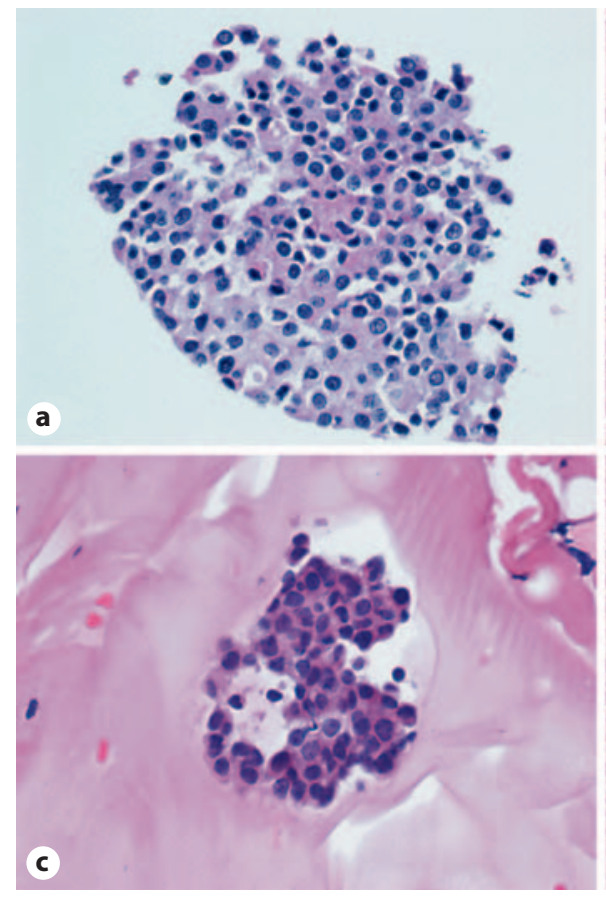

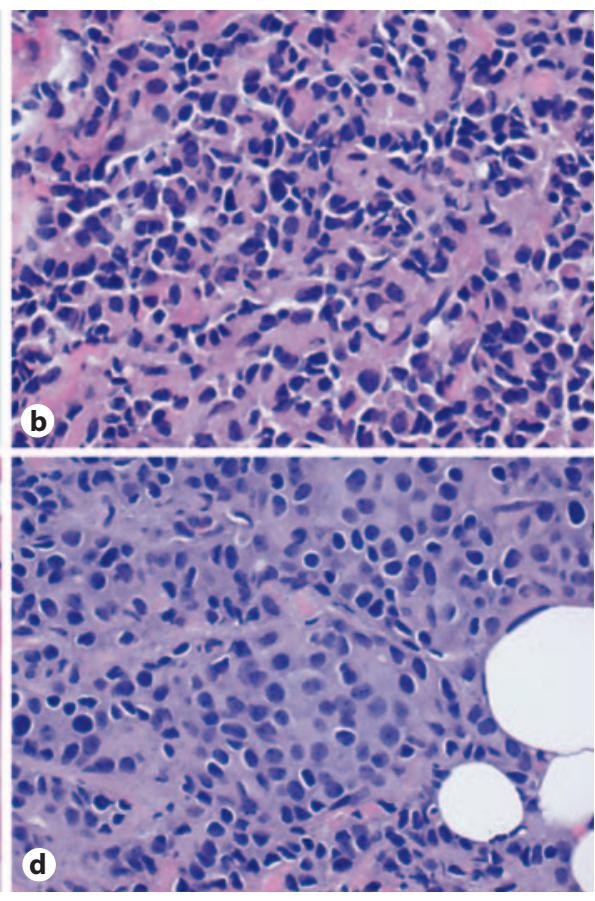

Statistical Analysis

The results of ER, PR, HER2 and MIB-1 IHC performed on the three types of cell blocks were compared to each other and to the results of tissue IHC. The Fisher exact $\chi^{2}$ test was used to generate a $p$ value.

\section{Results}

Comparison of Performance of Cellient, Formalin, and Thrombin Cell Blocks

Cellient cell blocks with adequate cellularity were obtained for all 31 cases. Adequately cellular formalin cell blocks were obtained for 25 cases and adequate thrombin cell blocks were obtained for 23 cases. Twenty of the 31 cases had adequate cell blocks of all three types (fig. 1).

\section{Comparison of IHC Assay for ER}

IHC staining for ER on all three types of cell blocks showed $100 \%$ correlation with tissue results using the Allred scoring system (table 3) $[3,4]$. No false-negative or false-positive staining for ER occurred. The Allred system considers the proportion of nuclei staining (proportion score, $0-5$ ) and the intensity of the stain (intensity score, $0-3$ ) to generate a total score, ranging from 0 to 8 . Total scores of 3 or greater are considered positive. Decreased nuclear staining intensity was noted for Cellient cell blocks (fig. 2). However, IHC stains for ER and PR would still be considered positive as long as at least $1 \%$ of nuclei stained.

\section{Comparison of IHC Assay for PR}

IHC staining for PR on Cellient cell blocks showed 80.6\% correlation with PR immunostaining performed on tissue sections (table 3). The $19.4 \%$ of cases with discordant staining (false-negatives) were all PR-positive on tissue sections and PR-negative on Cellient cell block sections (table 3). PR staining on formalin blocks showed $100 \%$ correlation with tissue results. The Fisher exact $\chi^{2}$ test showed a significant difference (two-tailed $p=0.0281$ ) between Cellient and formalin blocks. Results on thrombin cell blocks showed $86.3 \%$ correlation with results on tissue sections, but a statistically significant difference was not detected. As with ER, decreased intensity of nuclear staining was noted but did not affect interpretation as PR-positive or PR-negative (fig. 3).

\section{Comparison of IHC Assay for HER2}

Twenty-two of the cases were negative (score 0 or $1+$ ) for HER2 overexpression by IHC. Four cases showed equivocal IHC staining (score 2+) for HER2 overexpression. Fluorescence in situ hybridization (FISH) was negative for HER2 gene amplification in all 4 of these cases. Two cases were positive for HER2 overexpression by IHC 
Fig. 2. IHC stain for ER performed on cell blocks and paraffin-embedded tissue. Each photo is representative of staining interpreted as: proportion $=5$, intensity $=3$. a Cellient cell block. b Formalin cell block. c Thrombin cell block. d Paraffin-embedded tissue block. Original magnification $\times 400$.

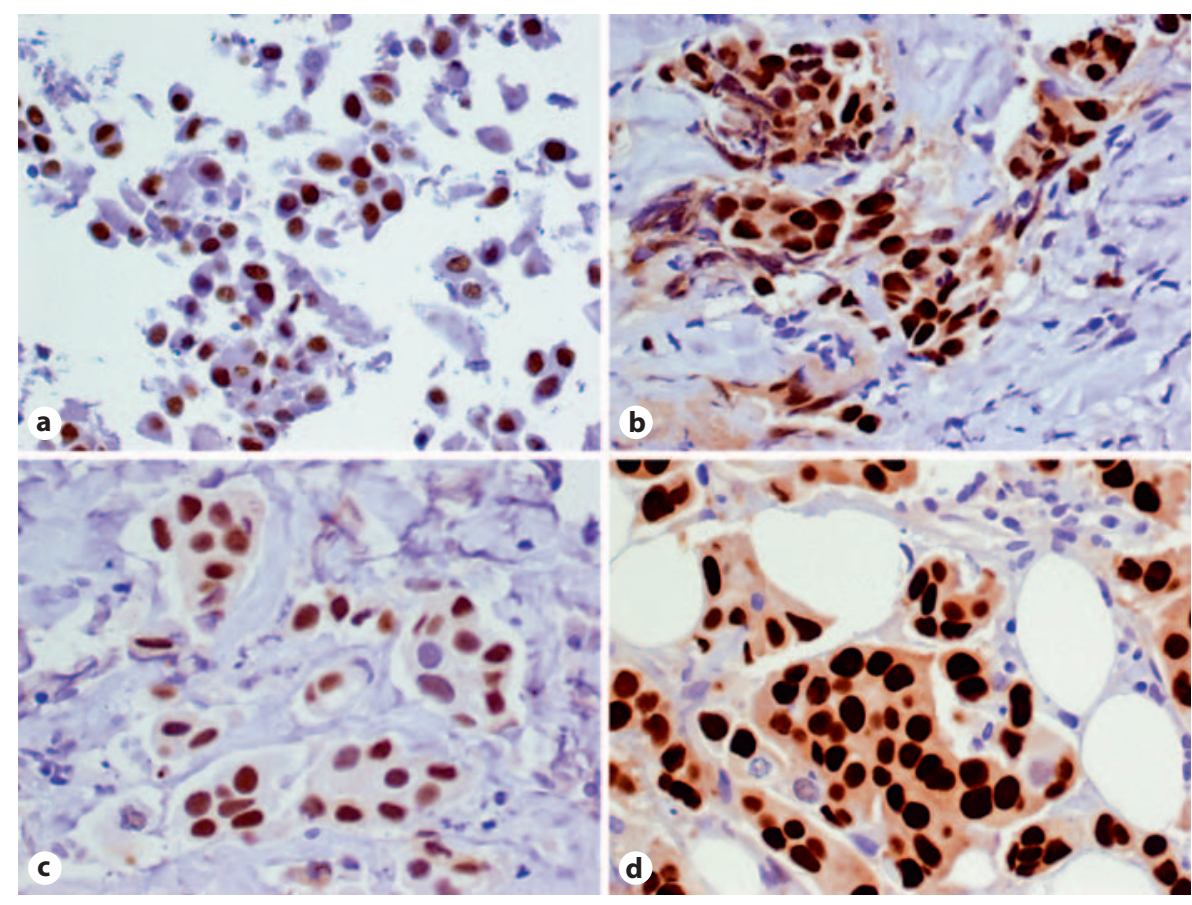

Table 3. Correlation between cell blocks and tissue blocks for ER, PR, HER 2 and MIB-1 IHC results

\begin{tabular}{|c|c|c|c|c|c|c|c|c|c|}
\hline & \multicolumn{3}{|l|}{ Cellient } & \multicolumn{3}{|l|}{ Formalin } & \multicolumn{3}{|l|}{ Thrombin } \\
\hline & correlation & FN & FP & correlation & $\mathrm{FN}$ & FP & correlation & FN & FP \\
\hline ER & $100 \%(31 / 31)$ & 0 & 0 & $100 \%(25 / 25)$ & 0 & 0 & $100 \%(23 / 23)$ & 0 & 0 \\
\hline PR & $80.6 \%(25 / 31)$ & $19 \%(6 / 31)$ & 0 & $100 \%(25 / 25)$ & 0 & 0 & $86.9 \%(20 / 23)$ & $13 \%(3 / 23)$ & 0 \\
\hline HER2 & $100 \%(31 / 31)$ & 0 & 0 & $96 \%(24 / 25)$ & 0 & $4 \%(1 / 25)$ & $100 \%(19 / 19)$ & 0 & 0 \\
\hline MIB- $1^{\mathrm{a}}$ & $100 \%(12 / 12)$ & 0 & 0 & $72.7 \%(16 / 22)$ & $18.2 \%(4 / 22)$ & $9.1 \%(2 / 22)$ & $70.5 \%(12 / 17)$ & $23.5 \%(4 / 17)$ & $6 \%(1 / 17)$ \\
\hline
\end{tabular}

$\mathrm{FN}=$ False-negative; FP = false-positive; MIB-1 = Ki-67.

${ }^{a}$ False-negative for MIB-1 is defined as a low $(<20 \%)$ MIB-1 result on cell block when corresponding tissue showed a high $(\geq 20 \%)$ MIB-1. False-positive for MIB-1 is defined as a high ( $\geq 20 \%)$ MIB-1 result on cell block when corresponding tissue showed a low $(<20 \%)$ MIB-1.

(fig. 4). IHC staining for HER2 performed on Cellient cell blocks showed $100 \%$ correlation with tissue results (table 3). IHC staining for HER2 performed on formalin and thrombin cell blocks showed 96 and 100\% correlation with tissue results, respectively (table 3). One case showed false-positive (score 3+) staining for HER2 on the formalin cell block. The corresponding Cellient and thrombin cell blocks were both negative for HER2 staining. The tissue section showed equivocal (score 2+) IHC staining for HER2 and subsequent FISH was negative for HER2 gene amplification.

\section{Comparison of IHC Assay for MIB-1}

MIB-1 staining was interpreted as either high or low with a cutoff point of $20 \%$ (fig. 5) [4, 5]. IHC staining for MIB-1 was performed on tissue sections of 26 of the 31 cases. Of these, 16 cases had a low and 10 had a high proliferation index. Technical issues, including loss of cells, occurred for several of the MIB-1-stained cell block slides, so fewer cases were available for interpretation. Twelve cases with Cellient cell blocks, 22 cases with formalin cell blocks, and 17 cases with thrombin cell blocks had MIB-1 IHC stains which were deemed acceptable 
Fig. 3. IHC stain for PR performed on cell blocks and paraffin-embedded tissue. a Cellient cell block interpreted as: proportion $=4$, intensity $=2$. $\mathbf{b}$ Formalin cell block interpreted as: proportion $=5$, intensity $=3$. c Thrombin cell block interpreted as: proportion $=5$, intensity $=3$. $\mathbf{d}$ Paraffin-embedded tissue block interpreted as: proportion $=5$, intensity $=3$. Original magnification $\times 400$.
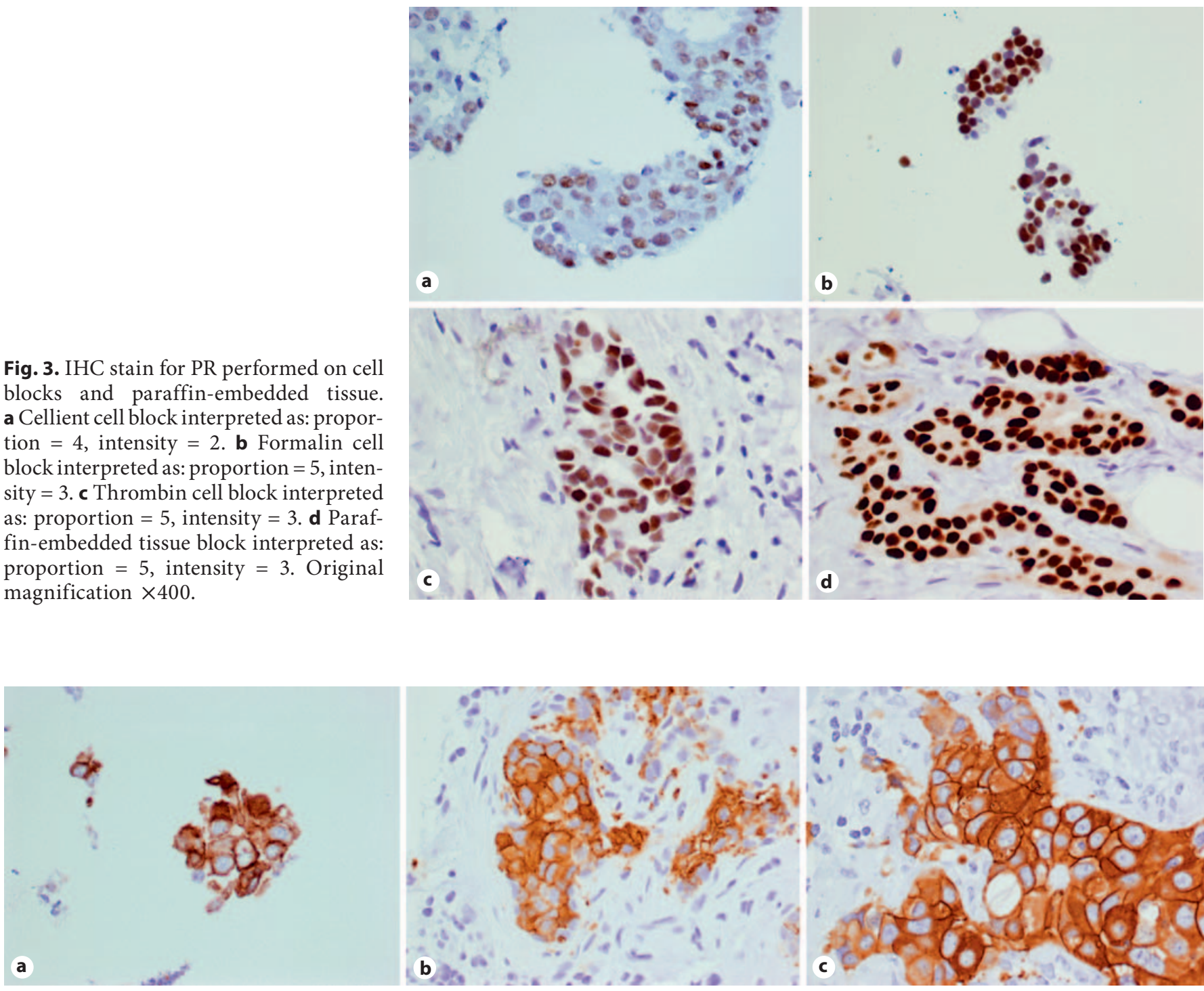

Fig. 4. IHC stain for HER2 performed on cell blocks and paraffin-embedded tissue, each interpreted as positive (3+) staining. a Cellient cell block. b Formalin cell block. c Paraffin-embedded tissue block. Original magnification $\times 400$. Insufficient tissue remained on the thrombin cell block to perform staining for HER2.

for interpretation. Of these cases, results on Cellient cell blocks had $100 \%$ correlation with tissue results. Results on $72.7 \%$ of the formalin cell blocks and $70.5 \%$ of thrombin cell blocks showed correlation with results on tissue sections. Among the formalin cell blocks, $18.2 \%(4 / 22)$ of the discordant cases were falsely low, while $9.1 \%(2 / 22)$ were falsely high in comparison to the corresponding tissue. Among the thrombin cell blocks, $23.5 \%(4 / 17)$ of the discordant cases were falsely low, while $6 \%(1 / 17)$ were falsely high in comparison to the tissue blocks (table 3).

Comparison of Breast Cancer Biomarkers

\section{Discussion}

The number of FNAs performed on breast lesions has decreased, partially due to the perceived inability to perform biomarker stains on cytologic samples. However, FNA is the most rapid, cost-effective and least invasive method of obtaining diagnostic material. Although limited for the diagnosis of invasion, FNA is indicated in the assessment of recurrent breast carcinomas. Our study demonstrates that results of IHC assays for breast carcinoma biomarkers performed on cytologic specimens 
Fig. 5. IHC stain for MIB-1 (Ki-67) performed on cell blocks and paraffin-embedded tissue. a Cellient cell block. b Formalin cell block. c Thrombin cell block. d Paraffin-embedded tissue block. Original magnification $\times 400$.

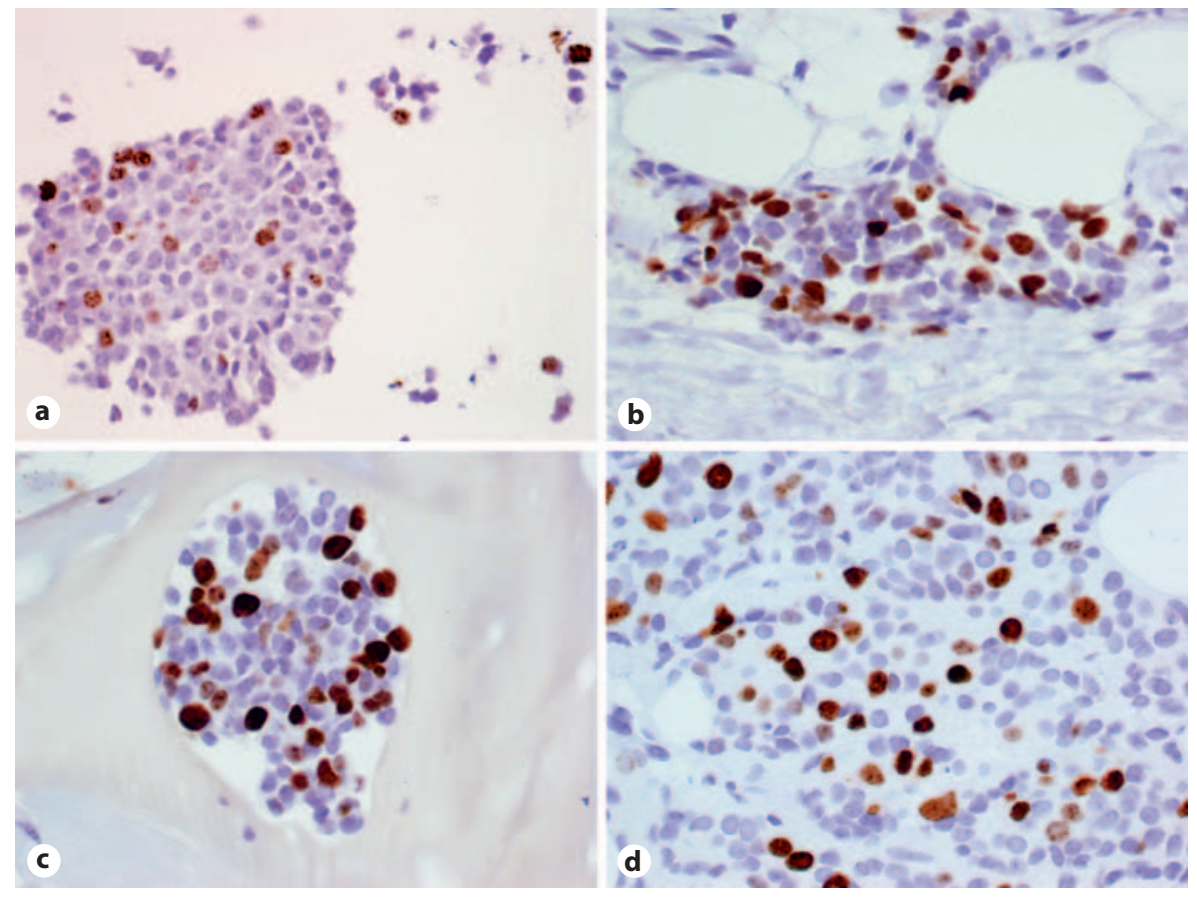

correlate well with the results obtained on tissue sections. Although Cellient cell blocks are not fixed in formalin, IHC staining for ER and HER2 performed on these cell blocks showed correlation with the formalinfixed tissue and the formalin-fixed cell block preparations. It should be noted that this study was designed to compare the performance of IHC stains on cell blocks made by different methods and was not designed to assess the efficacy of different methods of sample collection.

Many studies have compared the results of IHC staining for breast carcinoma biomarkers performed on cytologic smears and liquid-based preparations to those performed on tissue samples [6-12]. Numerous studies have investigated the effects of different fixation methods on both cytologic and histologic samples of breast carcinoma [13-20]. Few previously reported studies have compared the results of IHC assays of biomarkers performed on cell blocks to those performed on tissue [21, 22]. Recently, Shabaik et al. [23] demonstrated that ER, PR and HER2 performed on formalin-fixed cell blocks of FNA samples and of positive effusions reliably predict the status of the primary tumor. To the best of our knowledge, this is the first study comparing IHC assays for breast carcinoma biomarkers performed on cell blocks made by three different methods to those performed on tissue sections.
As the most recent advance in cell block technology, the Cellient system is not yet widely used and has few references in the literature [24,25]. Similar to the findings of Akalin et al. [25], we noted that cell blocks prepared using the Cellient system consistently produced blocks of adequate cellularity. Adequate Cellient cell blocks were obtained for all 31 cases, even those in which thrombin and formalin cell blocks were unable to produce an adequately cellular block. This finding contrasts with the findings of Wagner et al. [24] who found overall lower cellularity in Cellient cell blocks compared to traditionally prepared cell blocks. The cytomorphology of tumor cells was comparable among the three types of cell blocks in our study, although Cellient cell blocks showed a crisper nuclear detail than the formalin and thrombin cell blocks.

IHC staining for both ER and PR had decreased nuclear intensity on Cellient cell blocks in comparison to the formalin-fixed cell blocks and tissue. Although the staining intensity was decreased, the proportion of nuclei staining was similar. Thus, the decreased intensity did not alter the interpretation of the stains in terms of overall positivity or negativity for ER or PR. However, this is an important caveat to consider in the interpretation of IHC assays for these markers on Cellient cell blocks. In addition,nuclear staining for MIB-1 showed decreased intensity. Wagner et al. [24] also noted decreased stain 
intensity for several IHC stains performed on Cellient cell blocks prepared from various samples but attributed the discrepancies to random error.

The only statistically significant difference in biomarker IHC staining occurred for PR between Cellient and formalin cell blocks. False-negative staining for PR was noted in $19 \%$ of the Cellient cell blocks. In a study by Hanley et al. [21], the authors noted a higher discrepancy rate between formalin-fixed core needle biopsies and cell blocks fixed first in ethanol and later in formalin for staining with PR than with ER. The authors also noted that alcohol fixation may alter the antigenicity of PR as all of the PR-negative cell block samples were found to be PR-positive when the IHC stain was performed on formalin-fixed tissue blocks. Another study by Williams et al. [22] compared formalin-fixed tissue blocks with cell blocks fixed first in ethanol and then in formalin and found $8.8 \%$ discrepancy for PR staining. This study also focused on discrepancies in HER2 IHC between formalin-fixed tissue and alcohol-fixed cell blocks. The authors noted that the discrepancies in HER2 IHC staining observed between the tissue and cell blocks may be due to ethanol fixation, resulting in spurious HER2 IHC staining in ethanol-fixed samples. A study by Beatty et al. [26] which compared HER2 overexpression on FNA slides fixed in formalin, ethanol and CytoLyt also found the HER2 IHC assay to be unreliable on smears in comparison to formalin-fixed, paraffin-embedded tissue. In contrast, our study showed only one false-positive IHC stain for HER2 which occurred on a formalin-fixed cell block. The corresponding Cellient and thrombin cell blocks for that case, as well as the tissue block, were all negative for HER2. The Cellient cell blocks showed neither false-negative nor false-positive results for HER2 IHC stains.

\section{Conclusion}

By comparing the results of IHC staining for breast carcinoma biomarkers performed on three types of cell blocks to those performed on tissue sections, we have demonstrated that cytologic samples, even those which are fixed in methanol, can provide results comparable to those obtained using formalin-fixed tissue. No statistically significant differences occurred between both types of formalin-fixed cell blocks, methanol-fixed cell blocks and tissue sections stained for ER and HER2. The Cellient cell blocks, which are fixed in methanol, provided results comparable to cell blocks and tissue fixed according to the ASCO/CAP guidelines. Our study supports the use of the Cellient system for determination of ER and HER 2 status. As our sample size is relatively small and we have only a few HER2-positive cases, we recommend more extensive studies, with a larger sample size, prior to widespread clinical implementation. Further studies are also needed to assess the correlation between biomarkers performed on Cellient cell blocks and tissue blocks from tumors with weaker ER and PR expression.

\section{Acknowledgements}

All authors were active participants in creating this work. This study was approved by The Methodist Hospital Research Institute Institutional Review Board (Pro00005709).

\section{Disclosure Statement}

There are no financial disclosures.

\section{References}

1 Hammond ME, Hays DF, Dowsett M, et al: American Society of Clinical Oncology/College of American Pathologists guideline recommendations for immunohistochemical testing of estrogen and progesterone receptors in breast cancer (unabridged version). Arch Pathol Lab Med 2010;134:e48-e72.

2 Wolff AC, Hammond EM, Schwartz JN, et al: American Society of Clinical Oncology/College of American Pathologists guideline recommendations for human epidermal growth factor receptor 2 testing in breast cancer. J Clin Oncol 2007;25:118-145.

-3 Phillips T, et al: Development of standard estrogen and progesterone receptor immu- nohistochemical assays for selection of patients for antihormonal therapy. Appl Immunohistochem Mol Morphol 2007;15: 325-331.

$\checkmark 4$ Allred DC, Harvey JM, Berardo M, Clark GM: Prognostic and predictive factors in breast cancer by immunohistochemical analysis. Mod Pathol 1998;11:155-168.

5 Veronese SM, Maisano C, Scibilia J: Comparative prognostic value of Ki-67 and MIB1 proliferation indices in breast cancer. Anticancer Res 1996;16:2717-2722.

6 Sauer T, Ebeltoft K, Pedersen MK, Karesen R: Liquid based material from fine needle aspirates from breast carcinomas offers the pos- sibility of long-time storage without significant loss of immunoreactivity of estrogen and progesterone receptors. Cytojournal 2010;7:24.

7 Troncone G, Panico L, Vetrani A, et al: cerbB-2 expression in FNAB smears and matched surgical specimens of breast cancer. Diagn Cytopathol 1996;14:135-139.

${ }_{8}$ Railo M, Nordling S, Krogerus L, Sioris T, von Smitten K: Preoperative assessment of proliferative activity and hormone receptor status in carcinoma of the breast: a comparison of needle aspiration and needle-core biopsies to the surgical specimen. Diagn Cytopathol 1996;15:205-210. 
9 Konofaos P, Kontzoglou K, Georgoulakis J, et al: The role of ThinPrep cytology in the evaluation of estrogen and progesterone receptor content of breast tumors. Surg Oncol 2006; 15:257-266.

10 Tafjord S, Bohler PJ, Risberg B, Torlakovic E: Estrogen and progesterone receptor status in breast carcinoma: comparison of immunocytochemistry and immunohistochemistry. Diagn Cytopathol 2002;26:137-141.

11 Cano G, Milanezi F, Leitao D, et al: Estimation of hormone receptor status in fine-needle aspirates and paraffin-embedded sections from breast cancer using the novel rabbit monoclonal antibodies SP1 and SP2. Diagn Cytopathol 2003;29:207-211.

-12 Lofgren L, Skoog L, von Schoultz E: Hormone receptor status in breast cancer - a comparison between surgical specimens and fine needle aspiration biopsies. Cytopathology 2003;14:136-142.

13 Gong Y, WF Symmans, Krishnamurthy S, Patel S, Sneige N: Optimal fixation conditions for immunocytochemical analysis of estrogen receptor in cytologic specimens of breast carcinoma. Cancer 2004;102:34-40.

14 Goldstein NS, Ferkowicz M, Odish E, Mani A, Hastah F: Minimum formalin fixation time for consistent estrogen receptor immunohistochemical staining of invasive breast carcinoma. Am J Clin Pathol 2003;120:8692.
15 Goldstein NS, Hunter S, Forbes S, Odish E, Tehrani M: Estrogen receptor antibody incubation time and extent of immunoreactivity in invasive carcinoma of the breast: the importance of optimizing antibody avidity. Appl Immunohistochem Mol Morphol 2007; 15:203-207.

16 Qiu J, Kulkarni S, Chandrasekhar R, et al: Effect of delayed formalin fixation on estrogen and progesterone receptors in breast cancer: a study of three different clones. Am J Clin Pathol 2010;134:813-819.

17 Khoury T, Sait S, Hwang H, et al: Delay to formalin fixation effect on breast biomarkers. Mod Pathol 2009;22:1457-1467.

-18 Oyama T, Ishikawa Y, Hayashi M, Arihiro K, Horiguchi J: The effects of fixation, processing and evaluation criteria on immunohistochemical detection of hormone receptors in breast cancer. Breast Cancer 2007;14:182188.

19 Allred DC: Issues and updates: evaluating estrogen receptor- $\alpha$, progesterone receptor and HER2 in breast cancer. Mod Pathol 2010;23:S52-S59.

20 Gown AM: Current issues in ER and HER2 testing by IHC in breast cancer. Mod Pathol 2008;21:S8-S15.

21 Hanley KZ, Birdsong GG, Cohen C, Siddiqui MT: Immunohistochemical detection of estrogen receptor, progesterone receptor, and human epidermal growth factor receptor 2 expression in breast carcinomas: comparison on cell block, needle-core, and tissue block preparations. Cancer 2009;117:279288.
22 Williams SL, Birdsong GG, Cohen C, Siddiqui MT: Immunohistochemical detection of estrogen and progesterone receptor and Her2 expression in breast carcinomas: comparison of cell block and tissue block preparations. Int J Clin Exp Pathol 2009;2:476480.

23 Shabaik A, Lin G, Peterson M, et al: Reliability of Her2/neu, estrogen receptor, and progesterone receptor testing by immunohistochemistry on cell block of FNA and serous effusions from patients with primary and metastatic breast carcinoma. Diagn Cytopathol 2011;39:328-332.

24 Wagner DG, Russell DK, Benson JM, et al: Cellient ${ }^{\mathrm{TM}}$ automated cell block versus traditional cell block preparation: a comparison of morphological features and immunohistochemical staining. Diagn Cytopathol 2011; 10:730-736.

-25 Akalin A, Lu D, Woda B, Moss L, Fischer A Rapid cell blocks improve accuracy of breast FNAs beyond that provided by conventional cell blocks regardless of immediate adequacy evaluation. Diagn Cytopathol 2008;36:523529 .

26 Beatty B, Bryant R, Wang W, et al: HER-2/ neu detection in fine needle aspirates of breast cancer. Am J Clin Pathol 2004;122: 246-255. 